\title{
TENDENCIAS ACTUALES \\ DEL INTERVENCIONISMO ESTATAL \\ Y SU INFLUENCIA EN LOS MODOS \\ DE ESTRUCTURACION SOCIAL
}

\section{Gregorio Rodríguez Cabrero}

\section{Introducción}

La intervención estatal keynesiana de las décadas pasadas fue un instrumento poderoso de estructuración social que alteró profundamente los modos clasistas de organización social. Bajo su influencia se estimularon, desarrollaron y reforzaron modos funcionales y corporativos en las elecciones económicas, privadas; en los sistemas de organización del trabajo fabril; en el establecimiento de la relación salarial y normas de consumo, y en los mecanismos de afrontar el conflicto social. La propia intervención del Estado keynesiano formó parte esencial de ese proceso, del que además fue juez cualificado junto al sector corporativo u oligopólico de la economía. El keynesianismo fordista superpuso a la organización clasista y comunitaria todo un artificio compuesto de burocracias, instituciones y corporaciones que hicieron más opacas e inexcrutables las viejas estructuras de clase aún presentes y condicionantes del acontecer social.

A la vez, bajo este sistema buena parte de las poblaciones europeas vivieron décadas de relativo bienestar, crecimiento económico sostenido y estabilidad política, como expresión del encuentro, contradictorio y a veces conflictivo, entre capitalismo y democracia.

Desde los primeros años setenta la intervención estatal keynesiana, sin ha- 
ber desaparecido, está siendo sujeta a profundas mutaciones que no sólo cuestionan su naturaleza, sino que, además, están redefiniendo la intervención estatal en los países centrales en conexión con el curso actual de la transnacionalización económica, la revolución tecnológica y de las comunicaciones, y los cambios en las formas de vida.

Nuestro punto de partida consiste en sostener que la crisis del Estado de Bienestar está potenciando un nuevo tipo de intervencionismo más activo y corporativo que forma parte de la lógica económica actual: Estado fuertemercado libre, y cuyos dos niveles de intervención se pueden sintetizar en activo intervencionismo industrial y falta de compromiso social. El desarrollo, aún limitado, de este tipo de intervencionismo está ya condicionando los modos de estructuración social, conectados con cambios culturales y políticos en los que aquí no podemos entrar en detalle, construyendo una suerte de sociedad bastarda caracterizada por el darwinismo social, la precarización de la fuerza de trabajo, la dualización social y la preeminencia de la sociedad corporativa.

Tal hipótesis, que bien mirada no oculta el desarrollo de una sociedad menos solidaria y menos libre, no puede hacernos olvidar el desarrollo tentativo, a veces explosivo, de contratendencias a la corporatización social y estatal, y que son expresión de nuevos modos de vida y cultura, en parte expresados por los nuevos movimientos sociales, como el desarrollo de la economía asociativa, la aspiración a la descentralización de los servicios públicos y las demandas de participación política no partidista, por poner algunos ejemplos. Sin embargo, aún es prematuro vislumbrar la incidencia real de esos u otros nuevos modos de cultura en la estructura social.

En base a este marco general de reflexión trataremos de aproximarnos a las nuevas tendencias del intervencionismo estatal y su influencia en la estructura social: a) Primero, definiremos la naturaleza y crisis del intervencionismo keynesiano. b) Segundo, trataremos de esbozar los ejes del intervencionismo estatal en la actualidad, refiriéndonos a los países centrales y señalando los rasgos generales del intervencionismo en los países del sur de Europa. c) Tercero, trataremos de ver de qué modo y por qué vías el intervencionismo estatal de hoy condiciona la estructura social de las llamadas sociedades desarrolladas o avanzadas.

\section{El intervencionismo keynesiano: naturaleza y crisis}

La era de la reforma social (1870-1945), con su largo período de conflictos abiertos entre naciones, clases y grupos sociales, se clausura con el surgimiento de un nuevo modelo de crecimiento económico y organización política: el keynesianismo. Este fue capaz de combinar capitalismo y democracia partidista articulando un modo de producción fordista; estableciendo una norma 
de consumo colectivo ${ }^{1}$; estructurando la integración del conflicto social vía concertación colectiva de capital y trabajo; extendiendo la participación política pluralista, y construyendo el Estado de Bienestar como lugar de articulación desigual o asimétrica de los diferentes intereses y conflictos sociales ${ }^{2}$.

El Estado keynesiano, en cuanto modelo general, se consolida como (período 1950-1973) eje cardinal del sistema económico y político, por razones conocidas y que esquemáticamente son: 1) El capitalismo de gran empresa o corporativo va a exigir una regulación de su actuación; la socialización de amplios costes económicos y sociales; la absorción de importantes producciones privadas, y una previsión a medio plazo de los intereses económicos mercantiles en un marco internacional relativamente smithiano. 2) También el Estado se va a implicar más activamente en la reproducción de la sociedad y del sistema capitalista asumiendo crecientes costes en los campos de la educación, sanidad y vivienda. Costes generados por el propio desarrollo del capitalismo corporativo y por la propia dinámica del industrialismo urbano y de la sociedad de masas. 3) Finalmente, las necesidades de integración social, el arbitraje del conflicto laboral, los efectos más virulentos del gigantismo urbano, la desarticulación o desintegración de lazos comunitarios y tradicionales, etc., han spotenciado la intervención del Estado.

De este modo, el Estado keynesiano-fordista, a la vez que solventaba los problemas de la demanda económica y conseguía un relativo pleno empleo, lograba que libertad económica y democracia política tuviesen su lugar de encuentro y contradicción en el seno del Estado, en cuanto eje aglutinador del compromiso interclasista de postguerra superador del liberalismo anárquico y de la planificación despótica.

El intervencionismo keynesiano tuvo pronto efectos sociales importantes que van a incidir de modo desigual en la estructura social de las sociedades capitalistas del centro y que, de modo general, podemos resumir así:

1. El Estado keynesiano, al asumir buena parte de los conflictos sociales transformándolos en conflictos redistributivos, favoreció el desarrollo del fordismo como forma de trabajo del modo industrial de producción. Si bien es cierto que los efectos sociales desmovilizadores de las dos guerras mundiales y el desarrollo tecnológico militar estimularon vivamente el sistema fordista, también lo es que la asunción por el Estado de cuotas importantes de conflicto social fue un apoyo decisivo al sistema fordista.

Este sistema configuró, como decimos, un modo de trabajo industrial y unas capas trabajadoras cualificadas en parte en el seno de lo que hoy deno-

${ }^{1}$ M. Aglietta, Regulación y crisis del capitalismo. La experiencia de Estados Unidos, Madrid, Siglo XXI, 1979; sobre la norma de consumo, véase la tesis inédita (UAM, Facultad de Ciencias Económicas) de Luis E. Alonso Benito, Proceso de producción y normas de consumo. Un análisis sobre la reproducción de la fuerza de trabajo en el capitalismo contemporáneo.

${ }_{2}$ G. Rodríguez Cabrero, «Fundamentos socioeconómicos y crisis del Estado de Bienestar», Revista de Servicios Sociales y Politica Social, núm. 0, 1984. 
minamos sectores productivos en crisis: siderurgia, naval, textil, química; o en relativo retroceso: automóvil. Sectores éstos fuertemente sindicados y con capacidad de negociación colectiva, y cuyas demandas utilizarán una doble vía. Las demandas económicas se expresarán progresivamente en un sindicalismo contractual (disciplina contractual), y las demandas políticas se canalizarán a través del juego de la democracia parlamentaria de partidos políticos interclasistas.

El fordismo, que transforma la disciplina fabril en disciplina contractual, va a potenciar un tipo de sindicalismo ampliamente movilizador, pero progresivamente segmentado y corporatizado, cuyos resultados más visibles tendrán lugar a partir de los primeros años setenta, cuando los efectos disciplinarios de la crisis hagan su aparición.

2. El segundo efecto del intervencionismo keynesiano será la politización de la economía. El Estado, con las obvias diferencias entre los países de la OCDE, tiene que asumir los costes progresivos de las economías de oligopolio; negociar prioridades con las corporaciones de intereses más influyentes; mediar asimétricamente en las negociaciones colectivas; en suma, coordinar y socializar a través de sus instituciones los diferentes intereses corporativos. La administrativización de la economía, hoy tan denostada por muchos sectores sociales y económicos, respondía a la lógica mercantil imperante durante las décadas pasadas: Keynes reinaba en los Estados nacionales, mientras Adam Smith lo hacía en el plano económico internacional.

La otra cara de la moneda será el proceso de mercantilización de la política. Con ello queremos mencionar de forma esquemática los procesos de instalación en el seno del Estado de múltiples intereses corporativos en pugna; las tendencias a la privatización de áreas y actividades del Estado; el flujo de información y recursos entre organizaciones estatales y privadas; la liza partidista con sus ilimitadas promesas electorales divorciadas de los recursos necesarios para su satisfacción; la funcionalización de las decisiones políticas, etcétera.

En cierto sentido, se podría decir que cuanto más se politiza la economía, más se mercantiliza la política, si bien el Estado utiliza contradictoriamente formas no mercantiles para estimular la lógica mercantil.

En todo caso, este doble y único proceso aquí apuntado ha jugado un papel capital en la consolidación de un entramado de estructuras corporativas de tipo económico y político que han modificado las estructuras sociales de los países occidentales de la OCDE. Pero a ello volveremos más adelante.

3. El tercer efecto consiste en la expansión de los derechos sociales como expresión de las necesidades de reproducción social y legitimación política de los Estados keynesianos. Las necesidades de integración social han favorecido el crecimiento del salario social, y de los gastos sociales en general, hasta llegar a constituir cerca de un 30 por 100 del PIB en 1980. 
Como han puesto de manifiesto diferentes investigaciones ${ }^{3}$, los gastos sociales más que lograr una distribución vertical de renta y riqueza han constituido un bloque amortiguador de las desigualdades más potentes. Los servicios sociales tienen una cobertura universal, pero su redistribución de renta más que vertical ha sido horizontal y en su seno han proliferado los grupos de interés ligados a intereses corporativos y de las nuevas clases medias funcionales. Precisamente, estas clases conectadas al doble y complementario proceso de expansión del gran capitalismo y del Estado, se constituyen, a través de algunos de sus estratos, en instrumentos de mediación política interesados en la expansión de los servicios estatales, estructurando corporativamente el funcionamiento de estos últimos, lo que genera, a menudo, centralización, opacidad en la gestión y alienación en la satisfacción.

La administración del salario social, estructuralmente hablando, ha paliado los efectos de desigualdad del sistema industrial de gran empresa, utilizando criterios relativamente tecnopolíticos o corporativos aplicados por las clases medias funcionales, mediadoras políticas cualificadas en el neocapitalismo keynesiano.

Estas tres grandes líneas de influencia del intervencionismo keynesiano en la estructura social: 1 ) expansión del fordismo ligado a la gran industria; 2) la politización de la economía/mercantilización de la política, y 3) el desarrollo de los servicios sociales bajo la gestión políticamente mediadora de las nuevas clases medias funcionales, caracterizan de forma general a las estructuras sociales de los países centrales.

Sin embargo, el intervencionismo keynesiano se ha manifestado, al menos, bajo dos formas predominantes: como intervencionismo corporatista y como intervencionismo estatista. Tipología rudimentaria que, desde luego, nos sirve para aproximarnos al análisis de los casos históricos concretos de los países de la OCDE, pero que en modo alguno puede hacer cumplida justicia de los peculiares avatares históricos de cada Estado en concreto. El detenernos en el análisis general de esas dos formas de intervención, corporatismo y estatismo, de sus diferencias y de sus semejanzas nos será de suma utilidad para comprender las nuevas tendencias del intervencionismo estatal que trataremos de definir en el siguiente epígrafe.

$\mathrm{El}$ intervencionismo corporatista, por su parte, ha sido más bien característico de los países norteeuropeos, y también del centro como Austria, de tradición liberal y cultura protestante, en los que, desde los años treinta, sindicatos, empresarios y Estado tratan de cifrar acuerdos básicos (contrato social) de modo funcional sobre salarios, productividad, arbitraje del conflicto laboral, etc. El Estado es más bien un árbitro de redes organizativas en compe-

${ }^{3} \mathrm{H}$. L. WILENSKy, The Welfare State and equality, University of California Press Berkeley, 1975; C. HEwIrT, "The effect of political democracy and social democracy on equality in industrial societies», American Sociological Review, vol. 22, 1977. 
tencia y conflicto generadas por la propia sociedad. De forma que, simplificando, el corporatismo es un modo de desarrollo tecnofuncional de dichas sociedades a las que el Estado se ve obligado a dar respuesta de forma arbitral.

A su vez, el intervencionismo estatista ha venido a ser un modo de coordinación imperativa de múltiples intereses sociales y económicos, y de dirección económica, muy a menudo directa, de países de gran tradición centralista (Francia), de industrialización tardía (Japón, Alemania, Italia) o situados en la periferia del capitalismo central (España, Portugal, Grecia). En estos últimos casos los regímenes despóticos modernos ${ }^{4}$ han asumido la dirección del crecimiento económico y del despegue de la industria, incorporando al interior del Estado intereses particulares, patronazgos y redes clientelares, haciendo del Estado, en ocasiones históricas, un instrumento de intereses económicos dominantes y un medio de exclusión de partidos, sindicatos y capas sociales.

Sin embargo, durante los últimos veinte años hemos sido testigos de un proceso de "relativa convergencia» en las formas de planificación de los diferentes países de Europa. Los países de tradición corporatista han aumentado extraordinariamente el peso de sus sectores públicos, e incorporado una mayor reglamentación estatal de la actividad económica privada propia de países de tradición centralista e industrialización tardía. A su vez, los países del sur de Europa, sobre todo España e Italia, han desarrollado estructuras económicas y organizaciones sociales más complejas y organizadas, superpuestas a las siempre presentes antiguas redes de patronazgo, y potenciando corporaciones de intereses en competencia negociada, bajo el arbitraje estatal.

Esta relativa convergencia merece ser considerada por cuanto corporatismo y estatismo van a ser componentes importantes de las políticas estatales de los años setenta y ochenta. Dicha convergencia relativa puede ser situada entre 1967-1974, período en el que se empieza a definir el tipo de intervencionismo actual: activo intervencionismo industrial y descompromiso social.

En efecto, entre el Tratado de Roma (1957) y 1967 el capitalismo europeo, superado el período de reconstrucción de postguerra, tuvo un crecimiento extraordinario, consolidó y amplió el modo industrial de gran empresa y desarrolló progresivamente el sector de servicios e información. Pero al final de ese período se habían producido importantes mutaciones que pusieron de manifiesto los límites de las políticas de demanda agregada keynesiana para responder con flexibilidad los cambios en el sistema productivo. Entre tales mutaciones tenemos: 1) la mayor capacidad de negociación sindical (fuerza estructural de la clase obrera); 2) la profundización progresiva de los rasgos transnacionales de las economías capitalistas, y 3) la remodelación relativa del sistema de competencia industrial: presencia activa de Japón y emergencia de

${ }^{4}$ B. Moore, Social origins of Dictatorship and Democracy, Harmondsworth, Penguin, 1973. Traducción al español en Península, Barcelona. 
los NPIs. Las tensiones inflacionistas y las oleadas huelguísticas del final de los años sesenta son las expresiones primeras de los límites del keynesianismo.

La respuesta del intervencionismo keynesiano en estos años (1964-1974) será contradictoria, por cuanto se definirá como un keynesianismo corporativo que desarrollará hasta sus límites las políticas keynesianas (vía corporatismo), a la vez que irá generando los instrumentos de su superación (vía estatismo).

Por un lado, las políticas keynesianas tendrán un importante desarrollo bajo múltiples presiones políticas (avances electorales de la socialdemocracia en el Reino Unido y Alemania, avance de la izquierda en Francia e Italia, incremento de la presión sindical europea), económicas (incremento de los costes de reproducción de la fuerza de trabajo, mayor competencia internacional, cierto declinar de las tasas de ganancia en sectores productivos claves) y sociales (mayor demanda aducativa, sanitaria y de vivienda). Son los años de la socialdemocratización corporatizante y benefactora de muchos países de la $O C D E$. El crecimiento del Gasto Público durante esos años, todavía sin graves problemas de financiación, es el mejor indicador del desarrollo cualificado de las políticas keynesianas.

Pero, por otro lado, todo un conjunto de medidas, económicas y políticas, como superadoras del keynesianismo, se irán abriendo paso. Sintetizando, tenemos que:

a) Económicamente, los Estados europeos adoptan políticas parciales que refuerzan las estructuras industriales, en la línea de una política estructural activa, a través del incremento de los gastos en $\mathrm{I}+\mathrm{D}$ (Alemania), creación de organismos estatales de intervención industrial (IRC y NEB en el Reino Unido), mayor integración entre Estado y gran industria (Francia), y nacionalización de empresas (Suecia) ${ }^{5}$. En Italia ${ }^{6}$, la inversión industrial estatal en el Sur y el refuerzo, en general, del aparato industrial del Estado; en España, el II Plan de Desarrollo y el crecimiento de la Seguridad Social desde 1971 también apuntan en esa dirección, aunque se trate de un caso específico del intervencionismo ${ }^{7}$. En suma, el período 1967-1974 contempla el reforzamiento de la política industrial con un más activo intervencionismo estatal aún supeditado a políticas macroeconómicas de demanda en un contexto de mayor poder sindical y multinacionalización económica.

b) Políticamente, durante los años mencionados, se dan una serie de cambios dirigidos a integrar el conflicto social y reforzar los instrumentos estatales de intervención y control. La potenciación de mecanismos de representa-

${ }^{5}$ C. von OtTer, «Swedish Welfare Capitalism, the role of the State», pp. 142-164, en R. SCaSE, The State in western Europe, Londres, Croom Helm, 1980.

6 A. Graziani y E. Pugliese, Investimenti e disoccupazione nel Mezzogionno, Bolonia, Il Mulino, 1979.

7 Entre la múltiple bibliografía, véanse J. MuÑoz, S. Roldán y A. Serrano, La internacionalización del capital en España, Madrid, Edicusa, 1978; J. BraÑa, M. BuEsa y J. Molero, El Estado y el cambio tecnológico en la industrialización tardía. Un análisis del caso español, Madrid, FCE, 1984. 
ción funcional a costa de los de representación territorial, y el desarrollo cuantitativo y cualitativo de la centralización de las funciones del Estado, son ejemplos cualificados de lo que pretendemos decir o que refuerzan los componentes corporatistas (en el primer caso) y estatistas (en el segundo) de la intervención estatal.

Ambos géneros de procesos, reforzados en el período 1974-1980, van a potenciar y facilitar una intervención más directa y activa de los Estados de los países de la OCDE en el terreno industrial para apoyar un ajuste adecuado al nuevo contexto de poder transnacional.

En este proceso de convergencia de los modos de intervención del Estado y de respuestas contradictorias a los cambios sociales y económicos, el corporatismo y el estatismo, en relativa convergencia en los últimos tiempos, son, sin embargo, modos históricos propios de intervención que conviene tener presente:

a) El corporatismo, por su parte, no solamente es una estrategia política de concertación social o de acuerdos tripartitos entre Estado, sindicatos y organizaciones empresariales de amplio arraigo en los países norteeuropeos y práctica progresiva en los países del sur de Europa, sino que, sobre todo, es un modo de estructuración social propio de las sociedades industriales avanzadas cuyo desarrollo tiene su origen en cambios económicos, políticos e ideológicos interrelacionados entre $\mathrm{sí}^{8}$. Cambios económicos como son la oligopolización de las economías industriales con la presencia central de ła gran empresa en la actividad económica en profunda interrelación con el Estado interventor?.

El sistema de gran empresa demandará una mayor previsión económica, oficinas de planificación, órganos de mediación e instrumentos de concertación de precios y salarios. También cambios políticos en consonancia con los económicos, como son el relativo desplazamiento del Parlamento por el poder ejecutivo y el refuerzo, como anteriormente dijimos, de la representación tecnofuncional frente a la político-territorial. Estos cambios suponen una concentración en el Estado de la función de legitimación, un reforzamiento de las instituciones estatales de información y control y una difuminación de las fronteras entre lo público y lo privado.

El corporatismo liberal, al que podemos identificar con los cambios antedichos, fue estimulado, como señalan diferentes autores ${ }^{10}$, por factores como: un alto grado de centralización sindical y un marco legal favorable a la concertación social; la existencia de gobiernos socialdemócratas que apoyaron

${ }^{8}$ Un resumen en lengua castellana sobre los diferentes enfoques del corporatismo se puede ver en Carlota SolÉ, «El debate corporatismo-neocorporatismo», REIS, núm. 26, abril-junio 1984.

9 J. K. Galbrait H, Anales de un liberal impenitente, Barcelona, Gedisa, vol. I, 1982, pp. $17-35$.

10 P. SCh mitTer y G. Le h MBRUCh (eds.), «Trends towards corporatist intermediation», en Contemporary Political Sociology, Londres, Sage Publications, vol. I, 1979. 
fórmulas de consenso corporatista, y los efectos de la ideología socialdemócrata en la acción sindical con su énfasis en la planificación y el rechazo de la lucha de clases.

Como estrategia política se planteará su posibilidad de aplicación a partir de 1974 , pero los límites económicos y políticos que generará, como veremos en el epígrafe siguiente, reducirán su viabilidad a soporte de estrategias activas de estatismo industrial.

b) El estatismo como modo de intervención del Estado caracteriza, con obvias diferencias, a países como Francia, Italia, España, Grecia. El Estado en estos países ha cumplido un papel determinante en los procesos de crecimiento económico, como soporte del capital financiero y del proceso de modernización, a través de períodos de agudos conflictos sociales y exclusión política de minorías sociales y políticas ${ }^{11}$. Son países de sindicalismo dividido, débil, a pesar de lo cual ha solido ser un sindicalismo radicalizado. Se trata, además, de un tipo de intervencionismo que, como en el caso de España e Italia, ba acometido el proceso de modernización social superponiéndose a $y$ asumiendo las viejas redes clientelares y poderes tradicionales. Por último, las políticas keynesianas de pleno empleo y dirección económica han fomentado durante los años sesenta y primeros setenta la creación de modos corporatistas de decisión política y estructuración social.

Hay que señalar que en los países de tradicional intervencionismo estatista, la incorporación de modos corporatistas de decisión económica y política no ha supuesto la ruptura con viejas instituciones políticas y estructurales tradicionales de poder, sino, como señala Petras ${ }^{12}$, la agregación contradictoria y complementaria, al mismo tiempo, del llamado Estado histórico (aparatos canalizadores del patronazgo político y el clientelismo), el Estado jurídicorepresivo (instituciones garantes de la propiedad privada) y el Estado keynesiano (instituciones económico-financieras de contenido tecnocrático y modernizador), actuando en el mismo espacio de forma complementaria y a veces excluyente y conflictiva. Estas tensiones ayudan a explicar las ineficacias añadidas que provoca la pugna en el Estado entre el patrimonialismo precapitalista y el racionalismo neocapitalista.

Por último, los Estados latinos, con mayor o menos intensidad en función de su grado de modernización y subordinación al capital extranjero, afrontan retos propios en el proceso de transnacionalización económica que tienden a arrastrar a dichos Estados hacia una mayor integración en el centro capitalista, si bien acompañados también con lo que parece ser una mayor subordinación

"S. GINER, «Political economy, legitimation and the State in Southern Europe», British Journal of Sociology, vol. 33, núm. 2, 1982.

${ }_{12} \mathrm{~J}$. Petras, «Class and political-economic development in the Mediterranean: an overview», conferencia; «Social classes, social change and Economic Development in the Mediterranean», Atenas, mayo 1984, de próxima publicación en Fundación de Estudios Mediterráneos; A. ORTI, «En torno a una visión de Marx: clases medias y la construcción de la hegemonía burguesa», en Centenario de Marx, Madrid, Akal (en prensa). 
tecnológica y económica respecto del núcleo central. Este proceso en curso parece empujar a una mayor intervención estatal, a fin de adaptar los mercados internos a los nuevos cambios internacionales de la economía, sobre todo cuando variados sectores económicos pasan a manos de control extranjero y los viejos poderes financieros pierden protagonismo y privilegios frente a los vientos de la transnacionalización. Pero a ello volveremos más adelante.

Sin embargo, bajo fórmulas con predominio corporatista o estatista, el intervencionismo keynesiano ha alcanzado durante la década pasada unos límites económico-políticos que han llevado a su rechazo o, cuando menos, a su puesta en cuestión. Los mismos factores económicos y políticos que contribuyeron a fundamentar el Estado keynesiano del Bienestar son hoy, de forma contradictoria, factores que minan ese tipo de Estado ${ }^{13}$. De manera muy sintética, señalemos tales límites:

1. Límites de tipo económico. Con ello nos referimos al hecho de que el Estado keynesiano contribuyó a solventar los problemas de las crisis tradicionales de consumo del capitalismo. La creación de una demanda suficiente fue un objetivo prioritario de las políticas keynesianas de postguerra, y ello fue posible en un contexto de crecimiento y pleno empleo relativo de los recursos. Pero las políticas keynesianas de demanda provocaron a largo plazo problemas en el aparato productivo, especialmente en países relativamente estancados, en los que siendo correcta la demanda, sin embargo la oferta no se ocupaba de sí misma ${ }^{14}$. La competencia transnacional, el cambio tecnológico, el encarecimiento de las materias primas y la emergencia de los NPI, pondrán de manifiesto los límites de las políticas de demanda y los corsés administrativos del Estado de Bienestar frente al dinamismo del capitalismo.

Fundamental en las políticas de demanda es el Gasto Público como eje capital de socialización de la demanda. El Gasto Público de los países de la OCDE no ha hecho sino crecer de forma ininterrumpida durante los últimos veinte años. Su crecimiento es una de las expresiones más claras, sin duda, de los conflictos de intereses en el seno del Estado. La lucha por el Gasto Público, de obvios resultados desiguales para clases y grupos sociales (a pesar de su difícil cuantificación), la socialización de amplios costes de reproducción de la fuerza de trabajo, las expectativas ciudadanas en alza que se manifiestan a través de competencia política entre partidos políticos, y las presiones del capital corporativo sobre el Estado han conducido a la crisis fiscal o endeudamiento estructural de las Haciendas Públicas que provocan tensiones inflacionistas en las economías de gran alcance, máximo en un contexto de crisis

${ }^{13}$ Entre múltiples trabajos, véanse I. Goug $\mathrm{H}$, La economía politica del Estado de Bienestar, Madrid, H. Blume, 1982; C. OFFE, Contradiction of the Welfare State, Londres, Hutchinson, 1984; J. Ch evalier, «La fin de l'Etat Providence», Projet, núm. 143, 1980.

${ }^{14}$ R. Skidelski, El fin de la era keynesiana, Barcelona, Laia, 1982. 
que limita severamente, tanto económica como políticamente, el incremento de la presión fiscal.

2. Limites de tipo político. El Estado keynesiano ha generado en su desarrollo histórico límites para la propia reproducción de las economías corporativas. En primer lugar, el Estado de Bienestar ha potenciado la extensión de los derechos sociales, cuya expresión material son los servicios sociales de sanidad, educación, vivienda y Seguridad Social. Estos derechos, unidos a las necesidades de reproducción de la fuerza de trabajo y expansión de las clases medias funcionales, se expandieron durante las décadas pasadas considerándose derechos adquiridos y potencialmente ampliables. El paro estructural y el envejecimiento de las poblaciones han reforzado las expectativas sociales frente al «riesgo y el infortunio». Y es justamente el riesgo y el estímulo mercantil lo que la crisis está tratando, a su vez, de reforzar. Los gastos sociales deben reducirse en lo posible para destinarlos a usos "productivos», también hay que reducir las expectativas sociales o ciudadanas frente al Welfare State y, por último, la lógica mercantil debe formar parte del funcionamiento de los servicios sociales a través de los recortes de gastos y reprivatización de zonas de determinados servicios (pensiones, sanidad, educación). Tal es la lógica de las economías corporativas en la actualidad.

En segundo lugar, y en profunda conexión con lo anterior, tenemos que el pacto capital-trabajo de postguerra, que estableció la disciplina contractual o relación salarial fordista a través del arbitraje asimétrico del Estado, potenció la fuerza estructural de la clase obrera, su mayor fuerza negociadora y su capacidad de configurar un salario social importante. Pero ese pacto ha topado con los límites económicos del sistema, a partir de los primeros años sesenta, y se está redefiniendo en la actualidad a través de acuerdos que definan una disciplina corporativa basada en la moderación salarial y precarización de la fuerza de trabajo $y$, por otro, en la representación político-sindical segmentada de las capas asalariadas y en el logro de ventajas económicas para los núcleos más organizados del sindicalismo.

Por último, hay que señalar los límites que el proceso de burocratización del Estado impone a la actividad económica privada y a la representación política. Se trata de un proceso contradictorio, pues, por un lado, la centralización de las funciones del Estado y burocratización de la vida pública es una de las nuevas formas de coordinación imperativa de nuestros días en profunda conexión con el propio desarrollo de la economía corporativa. Pero, por otro, las burocracias públicas constituyen hoy coaliciones de representación funcional que, si bien canalizan y representan múltiples intereses privados, también constituyen corporaciones propias de poder que, a menudo, tienden a obstaculizar el dinamismo del sistema económico capitalista, a la vez que se superponen de forma cualitativa al sistema de representación político-territorial. Se podría decir que la tecnofuncionalización de las actividades del Estado es a la 
vez requisito y obstáculo a la lógica mercantil, pues se trata de un proceso que actúa en favor de dicha lógica, pero sin responder a su contenido propio.

3. Por último, tenemos los límites ideológicos que apuntan hacia una crisis de legitimidad del Estado de Bienestar. En esta dirección apuntan diferentes cambios sociales e ideológicos. Por un lado, el Estado de Bienestar es contestado por amplios sectores sociales por la oferta burocratizada de muchos de sus servicios, que contradice aspiraciones de descentralización y participación ciudadana. No se trata de la negación del Estado de Bienestar en cuanto tal, sino de la aspiración a que su oferta sea más descentralizada y participativa (aunque posiblemente estemos asistiendo a cambios más profundos, como luego veremos), no en vano el Estado Benefactor es un logro civilizatorio para grandes mayorías de población.

Pero, además, se ha producido una resistencia importante en el terreno fiscal por parte de importantes capas sociales, que no parecen estar dispuestas a asumir sin oposición la financiación de los costosos servicios públicos. Se trata de capas medias de población, aunque no exclusivamente, cuyos valores se centran en la ética del trabajo, prioridad del individuo y una cierta falta de compromiso social.

Por último, no ha sido baladí el debate académico en torno a estas cuestiones, particularmente la ofensiva de diferentes opciones situadas en el terreno del neoliberalismo. El monetarismo, public choise, etc., en un momento oportuno de insatisfacción colectiva frente al funcionamiento del Estado de Bienestar y de cambios tecnológicos y económicos, han magnificado la quiebra de dicho Estado, aunque, por otra parte, han dado lugar a un importante debate ${ }^{15}$ en el que aquí no podemos entrar.

Los límites económicos, políticos e ideológicos del modo de intervención estatal keynesiano, sumariamente señalados, ampliados y profundizados por los cambios estructurales en los sistemas productivos, han generado modos de intervención estatal diferentes que, a continuación, pasamos a analizar.

\section{Regulación económica y nuevas dimensiones estructurales del intervencionismo estatal}

Con el fin de poder contemplar las nuevas tendencias del intervencionismo estatal en los países de la OCDE es necesario, en primer lugar, analizar los rasgos generales de los cambios económicos estructurales en curso. Segundo, cuáles son las nuevas dimensiones estructurales del intervencionismo estatal. Tercero, las formas que este último está adoptando en la actualidad. Cuarto, trazar en sus grandes rasgos el modelo específico de intervención de los países latinos.

${ }^{15} \mathrm{~K}$. JUdge, "The growth and decline of social expenditure», en A. WaLKer, Public expenditure E Social Policy, Londres, Heinemann Educational Books, 1982. 
1. La naturaleza de la crisis actual se puede explicar como una alteración fundamental del sistema de regulación de postguerra, cuya contradicción fundamental resultante, simplificando al máximo, consiste en la incompatibilidad creciente entre las políticas nacionales keynesianas y el proceso de internacionalización de la producción. Se trata de dos procesos internamente unidos. El proceso de transnacionalización económica ha sido impulsado por la creciente competencia intracapitalista, la emergencia de los nuevos países industriales de disciplina fabril (Corea, Taiwan, Brasil, Singapur, Hong-Kong, etc.), el impulso tecnológico con sus posibilidades de fragmentación espacial y técnica y la flexibilidad del grupo empresarial multinacional para adaptarse a la lógica mercantil transnacional.

En cuanto a las políticas económicas nacionales keynesianas tienden a frenar el proceso de internacionalización y a osificar los espacios nacionales frente al dinamismo de la integración superior; ello tiene lugar a través de la persistencia de factores ya señalados, hoy en relativo retroceso, como la fuerza estructural de los sindicatos y el pleno empleo, el peso económico del Estado de Bienestar y la crisis fiscal, y la rigidez institucional del Estado keynesiano para adaptar sus políticas a los centros de decisión económica transnacional.

Las consecuencias de este proceso contradictorio, del que somos testigos desde hace una década, son claras ${ }^{16}$. Por un lado, la contradicción entre un esquema progresivamente transnacional y corporativo en el que actúan los sistemas económicos; por otro lado, las dificultades de coordinación económica en espacios nacionales de escasa coherencia económica en su interior. De este modo las políticas económicas keynesianas pierden autonomía y control sobre sistemas económicos progresivamente interdependientes e internacionalizados.

La rigidez que esto implica ha socavado las bases del intervencionismo keynesiano y, después de un período de políticas monetarias y fiscales de contención (1974-1979) y desbroce, la intervención del Estado está remodelándose en línea con los cambios en la DIT: el intervencionismo estatal actúa en la esfera microeconómica con un apoyo directo de aquellos sectores productivos que tratan de ajustarse a los nuevos imperativos del crecimiento transnacional, al mismo tiempo que el dinamismo transnacional demanda mecanismos de conrdinación imperativa superior. Es decir, la socialización de las relaciones económicas a escala transnacional demanda una "ordenación» de dicho proceso, cuyo correlato es la liberación social y económica a escala nacional bajo el signo del «desorden» (mercado libre) regulado por el Estado fuerte.

Si este planteamiento es correcto, sin entrar ahora en el análisis de los efectos fundamentales de la crisis (paro estructural, crisis fiscal, endeudamiento de los países en desarrollo y belicismo creciente), cabe preguntarse por los ejes básicos de regulación sobre los que están girando las políticas de intervención estatal y su desarrollo futuro.

${ }^{16}$ M. Aglietta, op. cit., y A. Mateus, "Internacionalização, crise e recessao», Pensamiento Iberoamericano, núm. 3, enero-julio 1983. 
La economía mundial vive en un proceso de transición, desde el modelo de crecimiento keynesiano hacia un modelo de crecimiento transnacional de profundas implicaciones económicas y políticas. Este modelo en emergencia se basa en una lógica de funcionamiento que supera las bases nacionales kevnesianas ${ }^{17}$ de decisión. Las políticas económicas de regulación nacionales ven limitada su autonomía en un contexto de economía transnacional, y las funciones de regulación e intervención estatal, tanto económicas como sociopolíticas, con ser aún claves, se sitúan ahora en la órbita de mutación del capital transnacional, y su transformación es en buena medida el reflejo del proceso de internacionalización.

Hipotéticamente, el modelo emergente de crecimiento transnacional, que como tendencia parece estar consolidándose, se caracterizaría por mecanismos de regulación que, en el plano nacional, integrarían: 1) un tipo de fordismo robotizado y fragmentado; 2) un Estado fuerte socialmente descomprometido; 3) un consumo individualista de masas ligado al desarrollo de las telecomunicaciones e informática; 4) una disciplina industrial corporativa con periferias internas de disciplina fabril en sectores en retroceso o en amplios grupos de fuerza de trabajo precarizada y, por último, 5) una política económica integrada y dependiente de los procesos transnacionales.

En el plano internacional los mecanismos de regulación serían un sistema mundial más integrado a la vez que fragmentado con amplias periferias dependientes; mercados transnacionales regulados desde el centro por una economía de servicios, y una coordinación imperativa monetaria, bajo liderazgo USA, o bien un sistema regional de poderes (USA, CEE y Japón).

En este modelo de crecimiento capitalista las políticas económicas estatales perderían parte de su autonomía, pero, al mismo tiempo, tendríamos un activo intervencionismo estatal en apoyo de una mejor relocalización de los capitales nacionales en el entramado económico transnacional. Tales serían las dos caras del intervencionismo estatal.

2. ¿Cuáles serían, entonces, las nuevas dimensiones concretas del intervencionismo estatal actual? Parece razonable suponer que la crisis actual no es tanto la crisis del sistema capitalista cuanto la quiebra del modelo keynesiano y del marco espacial e institucional de los Estados nacionales en los que predominantemente actuaba el sistema de mercado.

El modelo transnacional emergente se manifiesta, por un lado, como proceso de relocalización de los procesos productivos, desconponiéndolos en enclaves articulados que aprovechan fuerzas de trabajo disciplinadas, descualificadas y baratas en los NPI, rentabilizando viejos, e incluso partes de los nuevos, sectores productivos sin riesgos excesivos y que indirectamente contribuyen a la disciplina laboral en el centro del sistema. Por otro lado, en los

17 P. Dockes y B. Rosier, "Crisis y transformación del capitalismo», en Rupturas de un sistema económico, Madrid, H. Blume, 1981. 
países del centro, el Estado se orienta en la dirección de un compromiso activo con los procesos de crecimiento transnacional y, en concreto, con la política industrial de oferta (políticas de ajuste), y en el logro de una mayor disciplina social (política de desbroce), favorecida por el menor ritmo de crecimiento económico y su consiguiente austeridad social desigual.

El Estado se implica activamente en la política industrial y la política social, de manera que las políticas neoliberales se basan en un activo intervencionismo estatal en el campo productivo, a la vez que son políticas de creciente descompromiso en el terreno social.

La estrategia intervencionista del Estado se puede concretar en dos grandes líneas de actuación:

A) Políticas de mercantilización que refuerzan el libre funcionamiento de las fuerzas de mercado, y particularmente el sector corporativo de la economía. Estas políticas actúan por vía del «desentendimiento» ${ }^{18}$ y suponen, por el lado de la política económica, reducir controles estatales sobre la economía y favorecer la disciplina mercantil de economías corporativas. Por el lado de la política social se tiende a constreñir el campo de la solidaridad, reduciendo los gastos sociales, privatizando servicios sociales rentables mercantilmente y precarizando la fuerza de empleo a través de su eventualización, flexibilidad contractual y de despido, y estimulando ideologías de competencia e individualismo.

B) Políticas de socialización que implican un compròmiso estatal activo con los requerimientos del sistema productivo y de la DIT. Desde la política económica, la intervención estatal supone un apoyo explícito al cambio industrial, reconvirtiendo sectores productivos vía apoyos financieros, planes de viabilidad, etc., o estimulando, compartiendo o protagonizando la creación de sectores productivos de futuro (informática, telecomunicaciones, robótica, biotecnología, industria militar, etc.). Desde el lado de la politica social se trata de limitar activamente las demandas salariales y sociales, a la vez que se fomenta un núcleo laboral integrado que va unido al desarrollo de las nuevas actividades del sector servicios, combinando con un mercado laboral segmentado. Como señala J. M. Vicent, el Estado, «a pesar de sus dimensiones tentaculares, trata de convertirse en un Estado libre, orientado por completo hacia la acumulación de capital y la eficiencia» ${ }^{19}$.

Estas vías de intervención no son lineales, por el contrario las asedian obstáculos y contradicciones. La reducción del tamaño del Estado no siempre es favorable al sector privado o, al menos, a segmentos del mismo. Tampoco hay que olvidar los límites políticos de la reducción de gastos sociales, las resistencias sociales a la reconversión productiva o las resistencias de grupos y

18 CheValier, op. cit. zo 1979.

19 J. M. VICENT, «L'Agonie de l'Etat Providence», Le Monde Diplomatique, mar- 
organizaciones a renunciar a sus privilegios fiscales. Resistencias éstas u otras posibles que limitan el impacto de la intervención estatal, agravando los problemas financieros del Estado.

En cualquier caso, el intervencionismo estatal de hoy está suponiendo una doble y complementaria actividad: reforzamiento del mercado, corporativo sobre todo, de forma fundamentalmente pasiva, y mayor estatificación de la economía de forma activa. La crisis ideológica y económica del Estado de Bienestar, ya que aún no podemos hablar en rigor de quiebra, se está resolviendo mediante la potenciación ideológica del mercado y una más activa presencia del Estado en la economía. Proceso que contribuye, sin duda, a politizar más aún la economía, al tiempo que el Estado tiende a privatizarse o, mejor aún, corporatizarse, bajo una mayor estatificación de la sociedad. De este modo, la difuminación de las fronteras entre lo público y lo privado contribuye a la creación de una sociedad bastarda y dual bajo un núcleo integrado de corporaciones privadas que tienden a articularse con las corporaciones públicas del Estado fuerte en un entramado difuso de poder que se superpone a la mítica sociedad civil.

3. Las formas que adopta el intervencionismo estatal en esta época de transición, crisis y cohesión, dependen de muchos factores históricos, sociales y económicos. Como aquí no podemos hacer análisis históricos concretos, adoptaremos una perspectiva general sobre las formas de intervención.

Después de la etapa monetarista keynesianizada de 1974-1979, los países de la OCDE se adentran en un proceso de ajuste estructural e intervencionismo de libre mercado. Los ajustes de tipo negativo de los años 1974-1979 suponían un importante drenaje de fondos públicos destinados a mantener viejos sectores productivos, así como igualmente impedían, en el caso europeo, una adecuada innovación tecnológica, si bien es cierto que tales ajustes crecían acompañados de una progresiva política de desarrollo y la aparición de nuevos sectores productivos.

Las nuevas tendencias de las políticas industriales se van a caracterizar por una intervención directa del Estado en la producción y diseño de nuevos instrumentos de regulación. Integración de recursos públicos de forma directa en los circuitos del capital productivo; reestructuración de empresas nacionales, reprivatizando las rentables y enfatizando en la eficiencia de las que producen inputs para empresas privadas, al tiempo que se invierte en sectores de tecnología punta y se garantiza la venta de productos de sectores avanzados por parte del Estado; promoción de recualificación de parte de la fuerza de trabajo excedente y financiación de buena parte del coste social del desempleo.

$\mathrm{El}$ intervencionismo estatal industrial de hoy, sin embargo, no apela a una destrucción creadora liderada por las fuerzas del mercado, y a la flexibilidad de los precios a la búsqueda de un nuevo equilibrio. Por el contrario, las economías y las sociedades se regulan ahora mediante mecanismos de negociación 
e integración corporativa entre grandes organizaciones de interés, que resuelven desigual, e incluso despóticamente, sus diferencias y fines.

Si el keynesianismo enfatizó la coordinación económica a corto plazo, ahora se trata de una coordinación a largo plazo que acentúa las diferencias y asimetrías entre grupos y organizaciones. La búsqueda del consenso corporativo en políticas industriales de largo plazo, necesariamente supone una resistencia por parte de los grupos perjudicados más organizados y, en todo caso, un consenso de resultados más desigualitarios socialmente debido al coste económico de la transnacionalización en los espacios nacionales (austeridad para grupos sociales numerosos, paro estructural juvenil y ampliación de las periferias sociales y territoriales).

Esta más activa e imperativa intervención del Estado se nos presenta con no escasas contradicciones. Así, económicamente, la diversidad de instituciones y organismos surgidos en el terreno de la política industrial, la diversidad de instrumentos y mecanismos, así como la proliferación de organizaciones de interés hacen difícil la coordinación consciente del Estado para ajustar el sistema productivo y desbrozar los obstáculos sociales al cambio tecnológico.

Igualmente son importantes los conflictos entre las políticas macroeconómicas e industriales de carácter permanente que en países con Estados más centralizados los menores costes sociales son, en principio, posibles gracias al retraso en la aplicación de la política industrial, y en países con Estados más descentralizados el protagonismo de la política industrial supone mayores costes sociales. Aunque la mayor o menor dependencia de un país en la DIT condiciona lo anteriormente dicho, como demuestra, en parte, el caso de España.

Pero, además, existen límites y contradicciones políticas en el presente intervencionismo estatal: a) La intervención estatal directa en sectores industriales en apoyo del mercado tiende a restringir y condicionar las fuerzas de ese mismo mercado. b) También este tipo de intervencionismo supone una suerte de relativa pérdida de autonomía para el Estado: en el interior, porque su compromiso activo con la política industrial le incapacita, en parte, para mediar y arbitrar en los conflictos que exigen una cierta autonomía, a la vez que esta última es puesta parcialmente en entredicho por su descompromiso relativo con la redistribución social. En el exterior, porque en un marco de socialización transnacional las políticas industriales se ven supeditadas a la competencia y poder de las grandes empresas internacionales para cuya captación inversora el Estado ofrece importantes recursos económicos. c) Por último, este tipo de intervencionismo mina los mecanismos tradicionales y las aspiraciones colectivas de participación política privilegiando la negociación corporativa de las decisiones económicas y políticas en el seno de la sociedad y el Estado. d) Reflexión específica merece el intervencionismo estatal en los países del sur de Europa. Italia, España, Grecia y Portugal son ejemplos de industrialización histórica dependiente, con muy obvias diferencias, en los que 
el Estado ha jugado un papel central en el proceso de modernización e indus. trialización en marcos socioculturales complejos y contradictorios y a lo largo de cursos históricos llenos de violencias y conflictos ${ }^{20}$.

Rasgo común a todas esas etapas es el papel activo del Estado, aunque su intervencionismo ha dependido de la relación con la estructura-social específica de cada país y el modo de integración en la división internacional. De forma que, extrapolando la explicación de Mouzelis sobre el caso griego, se podría decir, con los obvios matices, que los Estados latinos en cuestión se han movido y actúan conforme a dos posiciones contradictorias: por un lado, el Estado dispone de una relativa autonomía para potenciar el desarrollo económico capitalista, creando condiciones generales de expansión del capital, interviniendo de forma directa en los procesos de producción (creación del IRI en Italia, el INI en España) y facilitando la entrada del capital extranjero; pero, por otro lado, el Estado tiene una dependencia estructural ${ }^{21}$ que se explica por el reflejo en su seno de la desigual estructura social (gran capitalpequeño capital, sectores sociales capitalistas y sectores precapitalistas, democracia parlamentaria y redes de patronazgo y clientela, etc.) y de los constreñimientos del capital extranjero y la DIT sobre la intervención del Estado.

Esta tensión histótica entre autonomía relativa creciente de los Estados latinos y dependencia estructural debe buscar su explicación en la evolución histórica de sus estructuras sociales actuales, cuyos rasgos generales es preciso no olvidar.

En las sociedades latinas se han dado, durante las tres últimas décadas, una serie de factores de homogeneización económico-cultural importante respecto de los países de Europa. Así, los procesos migratorios en dirección Norte y el turismo centro-norte europeo en dirección Sur, junto a la entrada masiva de capital extranjero, sobre todo en la industria y los servicios, han favorecido el proceso de consolidación capitalista interno en esos países. Existen obvias diferencias: Portugal, con una economía de base colonial y una administración prekeynesiana, es el ejemplo más atípico que, sin embargo, ha desarrollado algunos enclaves industriales importantes en el seno de una agricultura precapitalista; Italia, el país más desarrollado de todos los latinos, trata de lograr su homogeneización mediante la industrialización del Mezzogiorno bajo el impulso directo del IRI ${ }^{22}$; en España, con la transformación de la agricultura durante los años sesenta, el crecimiento capitalista logra importantes avances de homogeneización de la sociedad española bajo un modelo de desarrollo desigual.

Pero el proceso de integración en el capitalismo centroeuropeo, uno de cuyos rasgos es la homogeneización, va acompañado de diferencias o desequili-

20 S. Giner y E. Sevilla GuZmán, «From despotism to Parliamentarianism: class domination and political order in the Spanish State», en R. SCASE, op. cit.

${ }^{21}$ N. MouzeLIS, "Capitalism and the Development of the Greek State», en R. SCASE, op. cit.

${ }_{22} \mathrm{G}$. Amato, Il governo dell'economia in Italia, Bolonia, Il Mulino, 1972. 
brios específicos en estos países, aunque en mucha menor medida se dan también en el centro capitalista. Tales diferencias son: 1) permanencia y reproducción de formas y relaciones precapitalistas de producción y distribución; 2) fragmentación de los procesos productivos y del desarrollo tecnológico en función de los lugares de penetración del capital extranjero o apoyos e inversiones del Estado en unas zonas a costa de otras; 3) importantes diferencias en la distribución de la renta y distribución de los recursos; 4) también, la importancia estructural de la pequeña producción, de forma que el progresivo proceso de salarización de estas sociedades no ha significado la drástica reducción de pequeñas unidades productivas y de redistribución, sino su mantenimiento en conexión con el primer proceso, adoptando a menudo formas encubiertas (la llamada economía subterránea que la crisis ha potenciado); 5) el peso indudable de las estructuras familiares (apoyo, ayuda económica, etc.) recreadas por la crisis, de forma que la consolidación de la familia nuclear en los países latinos no ha impedido el mantenimiento de los lazos de ayuda y apoyo familiar. Rasgos éstos que conforman sociedades duales superpuestas, sin que ello quiera decir que la homogeneización capitalista esté al mismo nivel que la diferenciación tradicional. La superposición de tendencias y sociedades ha tenido lugar bajo el impacto creciente de una mayor integración de los países latinos en el sistema capitalista, particularmente desde 1975 hasta hoy.

A ello habría que añadir que este proceso de homogeneización o integración está operando por vía de una mayor subordinación, es decir, de una mayor dependencia de la mayoría de esas economías del sur de Europa, no sólo respecto del centro capitalista europeo, sino también del dinámico proceso de crecimiento transnacional. Hoy esos países tienen que competir activamente con los NPIs de Asia y América Latina para ofrecer mejores ventajas institucionales, de infraestructura y especialización, y atraer así al capital extranjero.

La intervención del Estado en el proceso histórico de modernización económica y social a lo largo del último siglo y medio ha sido compleja y conflictiva, como demuestra Salvador Giner. El Estado ha intervenido construyendo una relativa autonomía para apoyar al capital nacional, sobre todo a partir de la Primera Guerra Mundial, extendiendo su campo de actuación e intensificando sus apoyos y proteccionismos. Pero la relativa autonomía ha sido muy a menudo inexistente (períodos de regímenes de excepción) y, en todo caso, habría que enfatizar en la relatividad de una autonomía en la que los instrumentos de arbitraje sólo se han desarrollado muy recientemente, una autonomía mediatizada por redes de clientelismo y patronazgo, una relativa autonomía de asimetrismo social, relativa ineficacia (incluso desde el punto de vista capitalista) y ausencia de controles democráticos. Su matizada relativa autonomía tiene que explicarse, en definitiva, por la protección económica del capital nacional de forma amplia y corporativa y por la mediación asimétrica, y a menudo escasamente legitimadora, de los conflictos sociales.

Es sólo recientemente cuando, de forma desigual en tiempo e instrumen- 
tos, la corporatización ha permitido el disponer de aparatos estatales de carácter más arbitral y redistributivos, cuya debilidad y limitaciones ha puesto de manifiesto la crisis actual. Pero la creación de aparatos estatales de carácter funcional y «técnico» durante los últimos lustros no ha tenido lugar mediante la desaparición del Estado instrumental y del Estado clientelar, sino mediante la adición compleja y, a veces, contradictoria de múltiples Estados.

Esta yuxtaposición de aparatos estatales implica procesos de decisión contradictorios, dando lugar a todo tipo de posiciones y negociaciones donde se entremezclan la lógica mercantil, los clientelismos tradicionales y la alienación de diversos sectores respecto del Estado. La reproducción de la lógica mercantil, apoyada por el Estado interventor, se ve de este modo «corporatizada» por redes clientelistas de sectores económicos y políticos, dando lugar a ineficacias, gigantismo burocrático y procesos políticos opacos, cuando no secretos.

Así, en el caso italiano, la resultante es un Estado archipiélago, como señala Donolo, en el cual el patronazgo y clientelismo (Estado histórico) juegan un papel decisivo; en Grecia esta yuxtaposición se manifiesta en la tensión histórica entre el modelo de integración parlamentario y el modo de exclusión del dominio despótico; en España, por el contrario, el resultado es un Estado altamente centralista con una gran autonomía de instituciones e intereses corporativos que presionan sobre el Estado según sea el desarrollo de sus intereses protegidos en una sociedad que, hasta hace poco tiempo, disponía de escasas redes organizativas de tipo político y social modernas.

La relativa autonomía específica de los países latinos se ve reforzada, además, por su dependencia relativa del capital extranjero; por sistemas fiscales en los que el fraude tiene un peso cualitativo; sistemas redistributivos deficientes, y servicios públicos de, a menudo, escasa rentabilidad social.

En este marco descrito, ¿cuáles son las perspectivas del intervencionismo estatal de los países latinos en un contexto de crisis?

Para responder a esta compleja pregunta hay que poner en relación la presencia creciente de la transnacionalización económica, las estrategias de intervención en los países centrales y la peculiaridad socioeconómica y política de los países latinos (el caso de Italia debe matizarse, pues es un país capitalista central con perfiles estructurales socioeconómicos de tipo mediterráneo).

Podemos afirmar que la estrategia intervencionista de los países mediterráneos es un caso específico de la seguida por los países centrales antes analizada, pero que, por ser países situados en la primera periferia del capitalismo en el que se han integrado progresivamente, se encuentran en una posición de subordinación relativa en cuanto a las salidas posibles a la crisis. $\mathrm{Si}$, por un lado, es posible que la mayor integración limite la potencialidad de las tensiones sociales de la reubicación en la DIT, por otro lado, una creciente subordinación económica y tecnológica respecto del centro del sistema parece ser la otra característica dominante. 
La reconversión de los viejos sectores productivos (acero, barcos, textil) es un proceso de tensión y generación de desempleo, más acusado, en conjunto, que en los países del centro; por otro lado, la viabilidad de los nuevos productos y ramas productivas depende mucho de las decisiones inversoras del capital extranjero que las supedita a las facilidades institucionales y económicas ofrecidas por los Estados. Esto, además, se agrava porque estos países no tienen un desarrollo tecnológico avanzado autónomo, ni tampoco disponen de las antiguas facilidades de mano de obra y salarios bajos de los años sesenta. La consecuencia es no sólo un crecimiento del paro, sino un mayor relativo estancamiento y altas tasas de inflación, que en los últimos cinco años no se explican sólo por las alzas salariales, sino por la protección de las producciones nacionales.

La integración de las economías mediterráneas en el modelo transnacional ha conducido a los gobiernos mediterráneos a adoptar aquellas estrategias que limitan la subordinación económica de sus países, dejando para más adelante la adopción de estrategias de reformas profundas. La lógica mercantil transnacional favorece la adopción de políticas monetarias keynesianas de desbroce combinadas con estrategias de oferta, más de reconversión que de reindustrialización. En suma, los países mediterráneos están aplicando un peculiar intervencionismo liberal de carácter modernizante.

a) La política de desbroce implica, como sabemos, la reducción de los salarios reales, el freno de expectativas sociales, el relativo deterioro de los estándares sociales de vida y la formación de un ejército industrial de reserva.

b) El intervencionismo estatal está operando flexibilizando, no sin dificultades políticas, un mercado de trabajo, ya altamente segmentado, apoyando activamente (financiera, fiscal e informativamente) a sectores económicos de cierto futuro y facilitando las condiciones que permiten un flujo de capital extranjero en sectores de tecnología avanzada.

c) Decimos modernizante porque los cambios económicos mundiales exigen un Estado menos sometido a las presiones de clientelas y corporativismos, más eficaz para poder adaptarse al modelo transnacional, lo que no quiere decir, ni mucho menos, un Estado más autónomo a largo plazo.

En cualquier caso, la transición del modelo transnacional está implicando activamente a los Estados del sur de Europa que, si bien ganan autonomía relativa en el interior para apoyar ese proceso, también parece ser a costa de una mayor dependencia de los centros transnacionales de poder.

\section{El intervencionismo estatal y su influencia en los modos de estructuración social. Algunas tendencias actuales}

Si el Estado de Bienestar contribuyó durante las décadas pasadas a configurar una sociedad estructurada del modelo ya señalado, que posibilitó el en- 
garce entre capitalismo corporativo y democracia parlamentaria, del mismo modo, el nuevo tipo de intervencionismo estatal parece estar condicionando los modos de estructuración social.

Ciertamente, los cambios en la estructura socioeconómica, a su vez, están condicionando los modos y formas de la intervención estatal. Lo que sucede es que la dimensión y centralidad del Estado interventor en las sociedades denominadas maduras tiene amplias repercusiones e incidencias en la estructura social. En todo caso, dadas las muy difusas fronteras entre Estado y sociedad, que el keynesianismo contribuyó a desdibujar ${ }^{23}$, bien podemos reflexionar sobre los nuevos modos de estructuración social pasando de la intervención del Estado a los cambios socioeconómicos, y viceversa.

Aquí vamos a hablar de tendencias posibles a la luz de los nuevos procesos sociales en curso que los años venideros confirmarán o desmentirán.

Nuestra hipótesis, planteada al inicio de estas páginas, es que la estructura social de las sociedades de capitalismo corporativo sometida a profundos cambios tecnológicos, económicos, demográficos y sociales, se está definiendo sobre cuatro ejes: 1) un eje económico: la precarización de la fuerza de trabajo y fin del pleno empleo; 2) un eje social: la conformación de una sociedad dual; 3) un eje ideológico: el darwinismo social, y 4) un eje político: la preeminencia de una sociedad corporativa interrelacionada con un Estado fuerte.

Estas tendencias nos sitúan actualmente en una especie de sociedad bastarda, donde las viejas coaliciones keynesianas, ya bastante maltrechas, conviven en sociedades vertebradas por dualismos y corporativismos socioeconómicos y Estados activamente intervencionistas en lo económico, socialmente descomprometidos y políticamente fuertes. Pasemos a desarrollar esta hipótesis de forma tentativa y esquemática.

1. En primer lugar, desde un punto de vista económico, asistimos al fin del pleno empleo y a la llamada precarización de la fuerza de trabajo. Los cambios tecnológicos de la última década están definiendo un nuevo modelo socioeconómico que, entre otras características, desplaza trabajo vivo del sistema productivo a ritmo acelerado (disminución del número de ocupados asalariados) y redefine la población activa en favor del sector servicios.

En el primer caso, estamos ante el hecho decisivo del paro estructural que afecta a millones de personas, de las que un porcentaje importante sobreviven con las prestaciones del seguro de desempleo, al menos en los países más sólidamente económicos de la OCDE. Al mismo tiempo, la política de oferta no sólo destruye trabajo innecesario para el sistema industrial, sino que, además, la innovación técnica que lo acompaña exige una correspondiente flexibilidad en el empleo, que se manifiesta en la multiplicidad de formas de contratación no permanente y con ritmos temporales muy diferentes. Tal es la esencia de la precarización.

${ }^{23}$ A. Wolf, Los limites de la legitimidad, Madrid, Siglo XXI, 1980. 
En el segundo caso, el retroceso del sector industrial tiene lugar en favor del sector de servicios. La transnacionalización económica actual se apoya, esencialmente, en el sector servicios, cuya expansión va unida al desarrollo de nuevas tecnologías de información (informática y telemática) ${ }^{24}$; este sector es el único capaz actualmente de generar empleo, si bien de forma limitada. Alrededor de este sector están girando en buena medida cambios que reflejan la precarización de la fuerza de trabajo, como son el desarrollo de la economía sumergida, el impulso a medio plazo en favor del trabajo a domicilio en el sector informático, que refuerza el individualismo y aislamiento de los ciudadanos favorecidos por las tecnologías de la comunicación y el ocio, y la posible mayor dependencia y descualificación del trabajo.

La precarización de la fuerza de trabajo anuncia, de algún modo, «el fin de la sociedad asalariada», en expresión de André Gorz ${ }^{25}$, en el sentido de fin del pleno empleo relativo, deterioro material del derecho al trabajo y dualización social.

2. Además, unido indisolublemente al proceso anterior, tenemos su expresión social: la dualización de la sociedad. En efecto, la precarización de la fuerza de trabajo y el fin del pleno empleo está alterando ła antigua estratificación social keynesiana. Ahora, la política de oferta capitalista ha redefinido el mercado de trabajo en, al menos, cuatro grandes segmentos o sectores: 1) El sector central o protegido en conexión con las industrias punta y los mercados transnacionales, que comprende técnicos y trabajadores cualificados, bien remunerados y relativamente organizados para negociar con patronal y Estado. 2) El sector secundario, centrado sobre industrias en declive como naval, siderurgia, textil, química, compuesto de trabajadores, en parte cualificados, que fueron el núcleo militante del sindicalismo durante los años sesenta y que hoy se enfrentan a la pérdida parcial de empleo vía reestructuración industrial. 3) El tercer sector situado en el área de los empleos terciarios, excepto banca y seguros, mal pagados y no cualificados, y también los empleos de la economía sumergida, en parte situados en el sector terciario. 4) Por último, tenemos la periferia de los parados y de los que buscan su primer empleo, sobre todo jóvenes y mujeres.

Esta segmentación podría dualizar la sociedad en dos grandes grupos sociales: los ciudadanos estables y los ciudadanos eventuales. Dualización que, además, está siendo reforzada por el descompromiso social del Estado en el terreno de la política social mediante la contención y restricción de los gastos sociales. Mientras el Estado de Bienestar estimuló el pleno empleo y apoyó activamente la integración social a través de un bienestar básico para todos los ciudadanos (los denominados derechos sociales) durante las décadas pasadas, ahora el Estado responde a los retos y exigencias del cambio tecnológico

24 M. CASTELLS, «Reestructuración económica, revolución tecnológica y nueva organización territorial en Estados Unidos», Alfoz, núm. 7, 1984.

${ }^{25} \mathrm{~A}$. Gorz, "El fin de la sociedad asalariada», El País, 6-I-85. 
recortando gastos sociales de integración social y política, y apoyando la reestructuración de viejos sectores o la creación de los sectores de futuro; flexibilizando también el empleo mediante leyes que liquidan la era del pleno empleo y potencian la precarización, y fomentando el dinamismo mercantil interno para lograr un mejor ajuste al nuevo mercado internacional.

La dualización de la sociedad nos pone de manifiesto los límites sociales y económicos del Estado de Bienestar en los países occidentales. El creciente descompromiso social del Estado ha abierto las puertas a la austeridad social segmentada y al desarrollo de modos colectivos de solución utilitarista de diversos problemas sociales. La política social se supedita a las exigencias de la política económica y las demandas sociales se constriñen en favor de las demandas del mercado transnacional, si bien es verdad que el envejecimiento de la población y el paro estructural limitan, por razones económicas y políticas, el impacto del descompromiso estatal en el terreno social.

En todo caso, como señala Gorz, la distribución del trabajo en la actualidad estratifica a la sociedad en un orden que no se corresponde con el tradicional análisis de clases, de forma que en la derecha se encontrarían las capas patronales, tecnocráticas, parte de los obreros cualificados y empleados de grandes organizaciones empresariales públicas y privadas, mientras que en la izquierda el amplio mundo del trabajo eventual y precario. Evidentemente, tal división es insuficiente en sí misma para explicar las complejas estructuras sociales de los países centrales, pero, sin duda, enriquece las perspectivas de los análisis de estratificación social clásicos, además de situar en el análisis de la estructura social hechos que parece serán estructurales en las décadas venideras, como es el paro estructural y el trabajo precario.

3. Ideológicamente, el fin del pleno empleo y el fin del sueño de sociedades más benefactoras e igualitarias, nos hacen pensar si estamos ante el fin de la reforma social iniciada en la época de Bismark y consolidada después de 1945, tras largos decenios de conflictos sociales abiertos.

La ideología dominante de nuestra época parece ser una suerte de darwinismo social mezclado con el retorno parcial a valores de la ética calvinista. Por un lado, sobrevivir es una realidad social para grupos de población situados en las periferias sociales que, en muchos casos, viven en las fronteras de la legalidad, provocando sentimientos de «inseguridad ciudadana» en el núcleo central de la sociedad, segmentos del cual demandan seguridad y un Estado fuerte.

Pero, además, capas medias de la población manifiestan una resistencia fiscal creciente frente al Estado de Bienestar y prefieren no pagar impuestos a disponer de servicios colectivos crecientes ${ }^{26}$. El repudio a la responsabilidad

${ }^{26}$ Por ejemplo, en España, un tercio de los encuestados (32 por 100) en la encuesta sobre la familia llevada a cabo por Oykos para la Dirección General de Acción Social, en noviembre-diciembre de 1984, sostiene que prefiere impuestos más bajos aunque se recorten servicios en sanidad, educación o seguridad social. 
del Estado en la esfera privada, facilitado por la burocratización de la vida pública, encuentra su respuesta en el auge del neoconservadurismo y en la promoción de los valores de individualismo y competencia. El descompromiso social del Estado es un reflejo y, a la vez, respuesta activa a estos cambios ideológicos.

Obviamente, el darwinismo social tiene fundamentos materiales observable. La adaptación de las estructuras económicas nacionales a los cambios económicos y tecnológicos transnacionales implica impulsar las fuerzas del mercado para encontrar su síntesis contradictoria en la socialización económica transnacional. Ideológicamente, ello comporta promocionar el espíritu de competencia a todos los niveles de la sociedad, que, si bien tiene aspectos positivos como el autoempleo y promoción de las empresas pequeñas y asociativas, mina las viejas aspiraciones de solidaridad social. También se promociona el espíritu individualista, reacción en parte frente a la corporatización de la vida social y política, y reforzado por las tecnologías de la comunicación, que socavan la comunicación social.

Por último, la promoción de la austeridad social. La era keynesiana fue la era de la sociedad de consumo y del hedonismo social frente a la ascesis calvinista en economías centradas en la resolución de los problemas tradicionales de la demanda. Ahora, la política de oferta exige austeridad social (salarios más bajos, recorte de servicios sociales) y una renuncia parcial al hedonismo keynesiano, particularmente para las capas sociales de la periferia, y la asunción de valores prácticos tradicionales.

4. Por último, políticamente, los límites del Estado de Bienestar han puesto en entredicho las viejas coaliciones keynesianas incrementadoras del Gasto Público y de la expansión de los derechos sociales, que socavan la ética del trabajo y el espíritu de responsabilidad individual.

El Estado keynesiano encuentra sus límites en factores complejos ${ }^{27}$, como el peso económico de las demandas sociales en detrimento de la política de oferta; la burocratización excesiva de los servicios públicos y el reglamentaris- mo de la vida pública; la disciplina contractual que reforzó el peso sindical de forma relativa con sus consecuencias económicas y políticas; la limitación de la participación política a través del modelo pluralista de partidos ${ }^{28}$, y el conflicto de las funciones tradicionales del Estado nacional con las corporaciones internacionales, que se desmetropolizan convirtiéndose en organismos tecnocráticos independientes.

El problema político central es la «gobernabilidad» de las sociedades, la limitación de las demandas sociales que contradicen las demandas de los aparatos económicos transnacionales de nuestros días. Favorecer la gobernabilidad

${ }^{27}$ G. Rodríguez CaBRERo, «La participación política en las sociedades industriales $o c$ cidentales: ciudadanos, partidos políticos y bienestar social», Pensamiento Iberoamericano, núm. 5, 1984.

${ }_{28}$ F. E. Cardoso y R. Prebisch, En torno al Estado y el desarrollo, México, Ceestem, F. Nueva Imagen, 1982. 
implica reducir la presencia de las coaliciones keynesianas en el Estado y reforzar la disciplina corporativa sobre la sociedad civil.

El Estado fuerte de esta década se apoya en una mayor limitación de la sociedad civil (el denominado pesimistamente fin de la sociedad civil) y en un refuerzo de la disciplina corporativa de las grandes organizaciones sobre la sociedad civil y la vida política, proceso reforzado por las limitaciones de recursos existentes y la militarización de las economías industriales.

En este proceso, la legitimación del Estado asistencial se pone en entredicho por una doble vía. Por un lado, sectores sociales de ciudadanos o, si se prefiere, los llamados nuevos movimientos sociales y los ciudadanos financiadores del déficit público, no encuentran terreno apropiado de participación política, expresión cultural y control de los servicios públicos. Por otro lado, muchas condiciones estatales se ven condicionadas por las corporaciones transnacionales que influyen o imponen decisiones económicas y políticas de relevancia. De este modo, tenemos que en la quiebra de las coaliciones keynesianas confluyen, al menos, tres crisis o límites: los límites financieros del Estado de Bienestar (la crisis fiscal); los límites de eficacia de este Estado, expresión de la cual, pero no única, es la burocratización de la vida estatal, y, por último, los límites de legitimidad del modelo keynesiano expresados por resistencias ciudadanas y corporativas al Estado keynesiano.

Estas tendencias, sumariamente apuntadas, están redefiniendo los modos de intervención estatal y, al menos a medio plazo, bien podremos ser testigos, como señaló Rosanvallon, «de una sociedad bastarda en la que el reforzamiento de los mecanismos de mercado coexistirá con el mantenimiento de rígidas formas estatistas y el desarrollo de un corporativismo social parcial. Este tipo de sociedad reposará sobre una adición de dualismos que va a producir, a la vez, una serie de bloqueos e injusticias. Sería socialmente insoportable y económicamente ineficaz» ${ }^{29}$.

Bien puede pensar el lector que estas tendencias presentan un cuadro sombrío del futuro de dos sociedades occidentales. Desde luego, no es más sombrío que el porvenir de buena parte del tercer mundo incapaz de salir del subdesarrollo y la dependencia en el marco de la actual división internacional del trabajo, y, en todo caso, se trata de un conjunto de tendencias que aún no son dominantes.

También existen tendencias que apuntan en sentido contrario, si bien débiles y con escasa capacidad de desarrollo, cuyas posibilidades no residen en el rechazo de la actual onda de innovación tecnológica, sino en su adopción y aprovechamiento, tales como: las aspiraciones de participación política; el control de la vida personal; las corrientes de economía asociativa y autoempleo; el reparto del trabajo con garantía de ingresos mínimos, y las nuevas corrientes por las que se orienta la calidad de vida. Pero todo ello requiere una posterior reflexión.

29 P. Rosanvallon, La crise de l'Etat Providence, París, 1981. 